
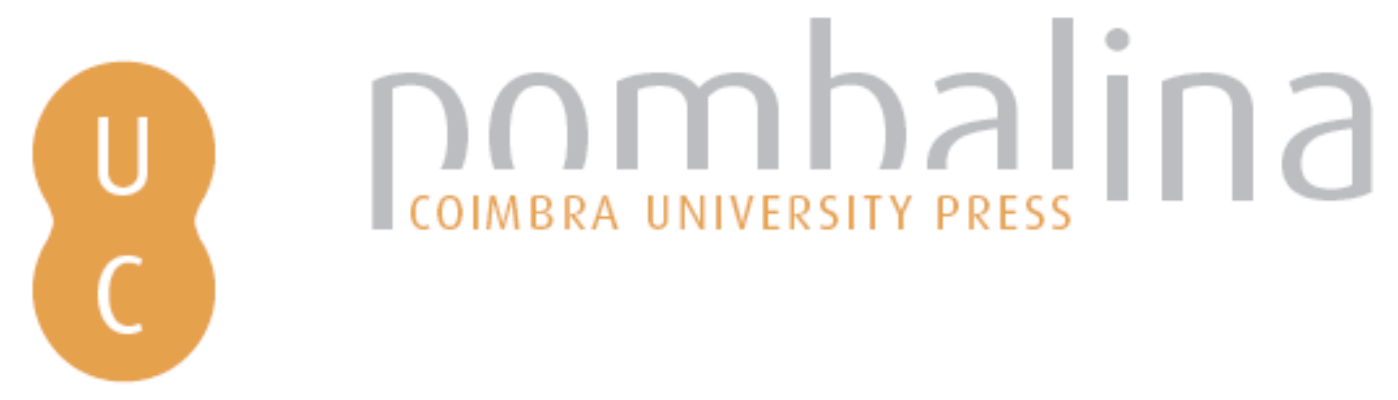

El Estado ante las graves violaciones de derechos humanos

Autor(es): Irigoyen Chávez, Sara

Publicado por: Imprensa da Universidade de Coimbra

URL

persistente: URI:http://hdl.handle.net/10316.2/47440

DOI: $\quad$ DOI:https://doi.org/10.14195/978-989-26-1524-0_16

Accessed : $\quad$ 26-Apr-2023 15:22:45

A navegação consulta e descarregamento dos títulos inseridos nas Bibliotecas Digitais UC Digitalis, UC Pombalina e UC Impactum, pressupõem a aceitação plena e sem reservas dos Termos e Condições de Uso destas Bibliotecas Digitais, disponíveis em https://digitalis.uc.pt/pt-pt/termos.

Conforme exposto nos referidos Termos e Condições de Uso, o descarregamento de títulos de acesso restrito requer uma licença válida de autorização devendo o utilizador aceder ao(s) documento(s) a partir de um endereço de IP da instituição detentora da supramencionada licença.

Ao utilizador é apenas permitido o descarregamento para uso pessoal, pelo que o emprego do(s) título(s) descarregado(s) para outro fim, designadamente comercial, carece de autorização do respetivo autor ou editor da obra.

Na medida em que todas as obras da UC Digitalis se encontram protegidas pelo Código do Direito de Autor e Direitos Conexos e demais legislação aplicável, toda a cópia, parcial ou total, deste documento, nos casos em que é legalmente admitida, deverá conter ou fazer-se acompanhar por este aviso.

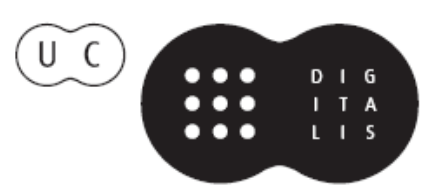


JOSÉ MANUEL PUREZA JOSÉ JUSTE RUIZ (COORDS.)
IMPRENSA DA

UNIVERSIDADE

DE COIMBRA

COIMBRA

UNIVERSITY

PRESS
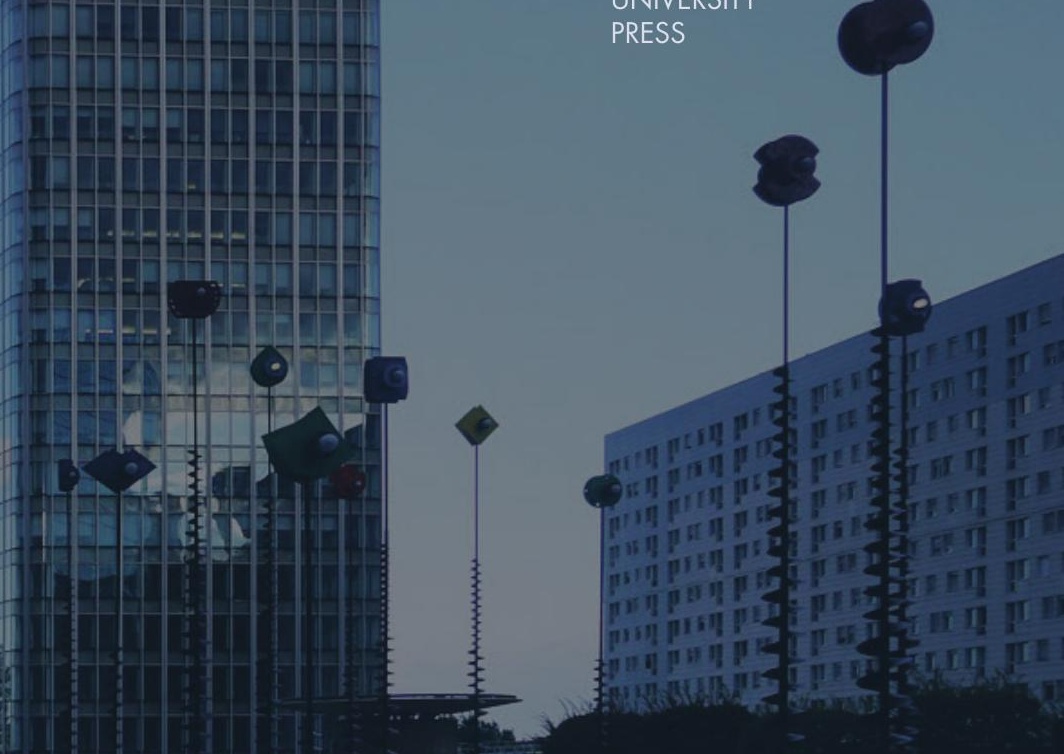

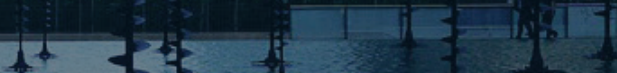

OS ESTADOS

EA ORDEM

INTERNACIONAL

CONTEMPORANEA

ATAS DO V ENCONTRO LUSO-ESPANHOL DE Professores de Direito internacional e RELAÇÕES INTERNACIONAIS 


\section{EL ESTADO ANTE LAS GRAVES VIOLACIONES DE DERECHOS HUMANOS}

Sara Irigoyen Chávez

\section{Alcance de las obligaciones estatales en materia de derechos humanos}

La fundamentación de la soberanía del Estado como responsabilidad se debe en gran parte al desarrollo y codificación de los derechos humanos en instrumentos jurídicos internacionales y regionales ${ }^{1}$.Su función principal ha sido imponer a los Estados obligaciones concretas para que la realización de los derechos humanos sea efectiva. Por tanto, los Estados son los principales encargados de cumplir las obligaciones en materia de derechos humanos. El efecto de estas obligaciones ha sido la limitación en el ejercicio de competencias estatales que antes se consideraban de exclusivo dominio estatal, es decir, las obligaciones en materia de derechos humanos pasan a formar parte del ámbito de su soberanía y la condicionan. Un análisis del alcance de las obligaciones que

${ }^{1}$ En este trabajo se presta especial atención a los siguientes tratados: universales: Pacto Internacional de Derecho Civiles y Políticos (1966), Pacto Internacional de Derechos Económicos, Sociales y Culturales (1966), Convención Internacional sobre la Eliminación de todas las formas de Discriminación Racial (1965). Convención contra la Tortura y otros tratos o penas crueles, inhumanos o degradantes (1975); y regionales: Convención Europea de Derechos Humanos (1950), Convención Americana sobre Derechos Humanos (1969). 
imponen los tratados de derechos humanos permite comprender la transcendencia de los derechos humanos para la nueva forma de entender la soberanía de los Estados y con más detalle las limitaciones que los Estados han asumido. Además, estas limitaciones afectan a los lindes de la actuación del Estado y el individuo en el Derecho Internacional actual (ver Pezzano, 2015: 305). Para analizar con detalle estas cuestiones se ha hecho uso de jurisprudencia e interpretaciones de diversos instrumentos y mecanismos internacionales, interpretaciones realizadas por los comités creados por las diversas convenciones y protocolos de derechos humanos,

y regionales, interpretaciones realizadas por el Tribunal Europeo de Derechos Humanos y la Corte Interamericana de Derechos Humanos. La razón de ello es mostrar la doctrina general de los principales instrumentos internacionales en materia de derechos humanos que al mismo tiempo permiten constatar la progresiva unificación a nivel internacional y regional de la interpretación y aplicación de las obligaciones emanadas de los derechos humanos. Dentro de los tratados regionales e internacionales de derechos humanos la doctrina ha identificado para su análisis tres categorías de obligaciones: la obligación de respetar, la obligación de proteger y la obligación de garantizar los derechos humanos (Ramcharan, 2011:124-135, Kälin y Künzil, 2009: 96-113).

\section{Obligación de respetar}

La obligación de respetar conlleva para el Estado una limitación en el sentido que impone una serie de obligaciones de abstención. Dichas obligaciones consisten principalmente en no realizar determinadas conductas que violenten los derechos humanos protegidos o no realizar conductas que impidan u obstaculicen el disfrute de los mismos, ya que todo ejercicio de poder público que se opone 
a un derecho reconocido por instrumentos internacionales constituye una violación. El Estado, por lo tanto, debe controlar todo ejercicio de poder de sus órganos estatales, entidades públicas o agentes estatales con el fin de que se ajusten a las obligaciones de abstención. En caso de incumplimiento de una obligación de control las posibles violaciones de sus órganos estatales serán imputables al Estado de acuerdo con los artículos 4-11 del proyecto de artículos sobre la Responsabilidad del Estado por actos internacionales ilícitos. Ejemplo de la obligación de abstención puede venir representado por la obligación del Estado de evitar que sus propias fuerzas de seguridad maten de forma arbitraria como parte del derecho a la vida ${ }^{2}$ de conformidad con el artículo 6 del Pacto Internacional de Derechos Civiles y Políticos (PIDCP). Ejemplos de la obligación del Estado de no obstaculizar la realización de los derechos pueden venir representada por la obligación del Estado de no proclamar la amnistía respecto a actos de tortura o negar el derecho a las víctimas de la misma a reclamar y obtener una compensación; no impedir a los detenidos o privados de libertad un acceso rápido y periódico a la asistencia por parte de médicos y abogados como parte de la prohibición de tortura u otros tratos inhumanos del artículo 7 del PIDCP 3 .

Por otro lado, dentro de la soberanía del Estado se encuentran también un conjunto de funciones impuestas por la constitución y normativa interna con el fin de salvaguardar los intereses generales y de terceros que requieren de intervención estatal, como puede ser salvaguardar la paz y la seguridad del Estado, el bienestar económico, la protección de la salud, la moral o los derechos. Este límite a los derechos humanos no es absoluto, sino que conllevará una ponderación en su aplicación ante cada caso concreto, que

\footnotetext{
${ }^{2}$ COMITÉ DE DERECHOS HUMANOS Observación General nº 6 (1982).

3 COMITÉ DE DERECHOS HUMANOS, Observación General no 19 (1990).
} 
en la práctica ha sido muestra de la creciente importancia de los derechos humanos frente a la soberanía de los Estados. Por tanto ambas obligaciones, la obligación de proteger los derechos humanos y la obligación de salvaguardar los intereses generales, deben ser consideradas conjuntamente. Sin embargo, existen derechos que bajo ninguna circunstancia pueden ser limitados sobre la base de intereses generales con el fin de evitar el riesgo de menoscabar su esencia, los llamados derechos absolutos, lo cual muestra la profunda erosión de la soberanía de los Estados en esta área, y un reconocimiento del interés internacional en su protección. Tampoco existe una libertad absoluta del Estado para restringir los derechos humanos sobre la base de intereses generales sino que dependiendo del interés en su protección para la comunidad internacional se han clasificado los derechos humanos en derechos absolutos con excepciones tasadas en los tratados y derechos que admiten ciertas limitaciones, siempre que dichas limitaciones cumplan con determinados requisitos. Así, ejemplo de derecho absoluto es la prohibición de la tortura (art. 7 PIDCP) ${ }^{4}$ que no admite ni acuerdo en contrario ni limitación alguna, ya que a juicio del Comité contra la Tortura, "en ningún caso podrán invocarse circunstancias excepcionales...como justificación de la tortura" (ver Kälin y Künzil, 2009: 101-102).

Otro ejemplo es el derecho a la vida que en principio parece un derecho absoluto, pero que en muy pocas y contadas excepciones admite la pena de muerte cuando el Estado desee regularla. La regulación de la pena de muerte debe contar con leyes que restrinjan su uso, no se aplique a menores de edad, se aplique solo como castigo de los delitos más graves y con rígidas medidas procedimentales ${ }^{5}$. Solo si cumple tales requisitos las restricciones al derecho a la vida

\footnotetext{
${ }^{4}$ COMITÉ DE DERECHOS HUMANOS, Observación General n ${ }^{\circ} 20$ (1992)

5 COMITÉ DE DERECHOS HUMANOS, Observación General nº17 (1989).
} 
serán lícitas, siempre que el Estado no se encuentre restringido por otros acuerdos como el caso del Consejo de Europa que ha prohibido expresamente la pena de muerte. Por último, la mayoría de los derechos humanos son susceptibles de limitaciones, en concreto, los tradicionales derechos civiles que protegen la esfera de la vida privada frente a la intervención del Estado (derecho a la vida privada y familiar, libertad de expresión, libertad de religión...) y los derechos políticos. Ahora bien, para garantizar que las limitaciones no son arbitrarias y evitar abusos, el Tribunal Europeo de Derechos Humanos (TEDH) ha estabelecido una serie de criterios para juzgar en cada caso concreto sobre la validez de las limitaciones en los derechos humanos (ver Kälin y Künzil, 2009: 101-102).

\section{Obligación de proteger}

La obligación de proteger se identifica con aquellas obligaciones de carácter positivo que emanan de los tratados internacionales de derechos humanos y conllevan el deber del Estado de adoptar medidas que permitan el disfrute libre y pleno de los derechos garantizados convencionalmente. Estas obligaciones tampoco son absolutas y pueden contemplar limitaciones al poder del Estado, ya que las obligaciones de protección implican una intromisión en cuestiones que antes eran de su exclusivo dominio y decisión. Además, la obligación de protección debe ser llevada a cabo por el Estado con la debida diligencia, es decir, el Estado debe tomar las medidas apropiadas para garantizar y castigar las violaciones de los derechos humanos. La adecuación entre las medidas adoptadas por el Estado y la protección del derecho humano correspondiente se evaluará por los Comités y tribunales que en cada caso corresponda y teniendo en cuenta todos los medios que tenga a su disposición el Estado concreto. 
Por lo tanto el Estado se ha limitado mediante unas obligaciones cuyo cumplimiento en la práctica será evaluado por mecanismos externos que ellos mismos han creado con este fin, comprometiéndose así mismo a adecuar y rectificar su ordenamiento interno en todo aquello que trasgreda las obligaciones que le corresponden.

La obligación de proteger del Estado se extiende a toda persona que se encuentre bajo su jurisdicción de forma que el Estado no tiene posibilidad de desligarse respecto a aquellos individuos o personas jurídicas que no se encuentren bajo su territorio, pero por razón de nacionalidad están sometidas al poder de organización del Estado. Así lo ha interpretado la Corte Internacional de Justicia en relación con el artículo 2 del PDCP en la Opinión Consultiva sobre la construcción del muro israeli en Palestina ${ }^{6}$. La razón de ser de esta interpretación es evitar que los Estados eludan sus obligaciones cuando ejercen su jurisdicción fuera de su territorio y, por tanto, limita la libertad extraterritorial del Estado. De esta afirmación deriva el deber del Estado de prevenir las violaciones de los derechos humanos en otros países, cuando por ejemplo los autores son empresas que se encuentren bajo su jurisdicción por tener en el Estado su principal sede o lugar de negocios tal y como ha sido puesto de manifiesto por numerosos comités al evaluar el comportamiento estatal ${ }^{7}$.

\footnotetext{
${ }^{6} \mathrm{CIJ}$, Consecuencias jurídicas de la construcción de un muro en el territorio palestino ocupado, Opinión Consultiva, Documento A/ES-10/273, Naciones Unidas, 2004, párr. 108-111.

7 COMITÉ DE DERECHOS ECONÓMICOS, SOCIALES Y CULTURALES, Observación General $n^{\circ} 14$ (2000), párr. 39; Observación General $n^{\circ} 15$ (2002), párr. 31; Statement on the Obligation of States parties regarding the coporate sector and economic, social and cultural rights, E/ C.12/2011/11, 20 mayo de 2011, párr. 5. COMITÉ PARA LA ELIMINACIÓN DE LA DISCRIMINACIÓN RACIAL, Observaciones finales para Canadá (2007), CERD/C/ CAN/CO/18, párr.17. COMITÉ DE DERECHOS HUMANO, Observaciones finales para Alemania (2012), párr. 16. Otras obligaciones similares pueden encontrarse en COMITÉ DE DERECHOS ECONÓMICOS, SOCIALES Y CULTURALES, Observación General n ${ }^{\circ} 12$ (1999), párr. 19; Observación General $\mathrm{n}^{\circ}$ 14 (2000), párr. 39; Observación General nº 15 (2002), párrs. 31, 35-36.
} 
La obligación de proteger del Estado incluye la defensa de los individuos frente a ataques de agentes estatales y frente a ataques de agentes privados que impidan la realización de los derechos humanos. Esta obligación supone un compromiso mayor de sus medios ya que debe orientarlos a la protección de todo individuo bajo su jurisdicción frente a todo posible tercero que pretenda la violación de sus derechos humanos. La protección debe de materializarse en medidas y normas nacionales tanto de prevención y protección ante posibles violaciones de derechos como de promoción de un ambiente propicio para su realización. Todo ello teniendo en cuenta siempre el principio de la debida diligencia ${ }^{8}$. Este parámetro permite examinar los casos individualmente y determinar si el Estado ha protegido o no en la medida de sus posibilidades (ver Ramcharan, 2011 :39-44; Ssenyonjo y Baderin, 2010:404-407)9 . El parámetro de la debida diligencia sirve de la misma forma para valorar las omisiones del Estado, ya que si un Estado omite la realización de un acto debido que hubiese tenido posibilidad de impedir una violación de los derechos humanos o hubiese mitigado el daño, puede atribuirse, dicha violación, al Estado aunque no hubiese sido el autor material de la misma ${ }^{10}$.

Hechas estas consideraciones es preciso tener en cuenta también los límites de la obligación de proteger del Estado para que no

\footnotetext{
8 Ver CORTE INTERAMERICANA DE DERECHOS HUMANOS, Velásquez-Rodríguez contra Honduras (fondo), 29 julio 1988, párr. 172.

9 Un ejemplo de ello véase en CORTE INTERAMERICANA DE DERECHOS HUMANOS, asunto "Panel Blanca" (Paniagua Morales y otros) vs. Guatemala, sentencia de fondo, 8 marzo 1998, párr. 171-173 COMITÉ DE DERECHOS HUMANO, Observación General n ${ }^{\circ} 31$ (2004), CCPR/C/DEU/CO/6, párr. 8.

${ }^{10}$ Ejemplo de ello es el caso tratado por el TRIBUNAL EUROPEO DE DERECHOS HUMANOS, E. and Other $v$. United Kingdom, appl. 33218/96, 26 noviembre 2002; TRIBUNAL EUROPEO DE DERECHOS HUMANOS, $A$. $v$. United Kingdom, appl. 100/1997/884/1096, 23 septiembre 1998. Otros ejemplos pueden ser encontrados en COMITÉ CONTRA LA TORTURA, Observación general nº2 (2007), párr. 18 (énfasis añadido). Un ejemplo de ello es el caso del TRIBUNAL EUROPEO DE DERECHOS HUMANOS, Asunto Opuz c. Turquía, appl. no. 33401/02, 9 de junio de 2009
} 
sea interpretado "in a way which does not impose an impossible or disproportionate burden on the authorities"11 y evitar que sea utilizado como un "cheque en blanco" para imponer restricciones arbitrarias con justificaciones basadas en la protección de los derechos humanos. Por ello el TEDH ha identificado determinados criterios que aplicados al caso concreto le permiten valorar la existencia de responsabilidad del Estado (ver Kälin y Künzil, 2009: 109-111).

\section{Obligación de garantizar}

El Estado tiene la obligación de garantizar el disfrute de los derechos humanos (art. 2.3 PIDCP), mediante recursos eficaces y accesibles. Esta obligación supone para el Estado una limitación en sus disposiciones legislativas, y la organización de su aparato administrativo y judicial con el fin de poner en funcionamiento recursos eficaces que permitan a los individuos reclamar las posibles violaciones de los derechos humanos en el orden internacional. El Comité de Derechos Humanos ha insistido en esta obligación como parte esencial de la debida protección del derecho a la libertad y seguridad personales, pero también para hacer realidad el derecho a la intimidad, la prohibición de la tortura u otros tratos degradantes ${ }^{12}$. Además de ello supone que en caso de que el Estado no sea capaz de satisfacer estas obligaciones por vía interna y cuando las violaciones tengan la característica de constituir graves violaciones de derechos humanos, el Estado deberá realizar acuerdos de colaboración internacionales para constituir un tribunal mixto, o deberá remitir a los culpables para ser juzgados por otros

11 TRIBUNAL EUROPEO DE DERECHOS HUMANOS, Osman $v$. The United Kingdom, Report, appl. no. 87/1997/871/1083, 28 octubre de 1998, párr. 115.

12 COMITÉ DE DERECHOS HUMANOS, Observación General n ${ }^{\circ} 8$ (1982), n ${ }^{\circ} 16$ (1988), no 20 (1992). 
tribunales internacionales $a d$ hoc a la Corte Penal Internacional o en caso de que las circunstancias lo aconsejen, podrán constituir una "Comisión de la Verdad".

En sentido negativo, la obligación de garantizar supone para el Estado por ejemplo la imposibilidad de declarar la amnistía por actos de tortura o tratos inhumanos o degradantes, ya que -de lo contrario- en tales casos la declaración de amnistía constituía una violación en sí misma ${ }^{13}$. Además, en los casos en los que una investigación revele violaciones de derechos humanos reconocidas como delictivas a nivel interno o internacional y no existan cauces para su enjuiciamiento, su mera existencia puede constituir una violación separada del Pacto ${ }^{14}$. Ejemplos de ello son el descubrimiento de delitos de tortura o tratos crueles, inhumanos o degradantes similares, ejecuciones sumarias y arbitrarias y la desaparición forzosa, sin ser juzgados, ya que el agravante en este caso proviene de que se trata de delitos cuya impunidad es desencadenante de repeticiones. Dentro de esta obligación es necesario destacar, como lo hace el Comité de Derechos Humanos, la suprema obligación de los Estados de no dejar impunes las violaciones más graves como parte de la prevención de las violaciones del derecho a la vida (art. 6 PIDCP). "El Comité estima que los Estados tienen la suprema obligación de evitar las guerras, los actos de genocidio y demás actos de violencia en masa que causen la pérdida arbitraria de vidas humanas ${ }^{15 "}$ (ver Ramcharan, 2011: 45-46). Por ello, algunos organismos de las Naciones Unidas, como por ejemplo el Consejo de Seguridad y el Alto Comisionado para los Derechos

13 Ejemplos de ello en la jurisprudencia: CORTE INTERAMERICANA DE DERECHOS HUMANO, asunto Barrios Altos vs Perú, sentencia sobre el fondo, 14 marzo 2001, párr. 41-42; CORTE INTERAMERICANA DE DERECHOS HUMANOS, asunto Gomes Lund y Otros vs. Brasil, 24 noviembre 2010, párr. 147-149; COMITÉ DE DERECHO HUMANOS, Observación General nº 20 (1992), párr. 8 y 15.

${ }^{14}$ COMITÉ DE DERECHOS HUMANOS, Observación General no 31 (2004), párr. 18.

15 COMITÉ DE DERECHOS huMANOS, Observación General nº 6 (1986), párr. 2. 
Humanos ${ }^{16}$ y tribunales regionales de derechos humanos ${ }^{17}$ han entendido que como parte de la prevención el Estado debe juzgar y no dejar impunes los actos de genocidio, crímenes de guerra, los crímenes de lesa humanidad o las infracciones graves de los derechos humanos sin que en ningún caso se pueda decretar una amnistía. En este contexto, la Corte Interamericana ha entendido que los Estados tienen la obligación de cooperar en estos casos mediante una extradición de los responsables o juzgándolos cuando el crimen haya sido cometido en algún Estado de la región. ${ }^{18}$

La obligación de garantizar condiciona competencias que antes se consideraban exclusivas del Estado, como por ejemplo la organización administrativa del Estado, con el fin de crear instrumentos efectivos de investigación; así como el compromiso de medios personales, materiales y económicos del Estado para sustentar el cumplimiento de estas obligaciones, especialmente las derivadas del PIDESC o la obligación de otorgar una determinada reparación en caso de que se declare la violación de un derecho humano. A mayor abundamiento, la obligación de garantizar incide en la organización administrativa del Estado de muy diversas maneras porque requiere que el Estado disponga de instrumentos y recursos para investigar las alegaciones de violaciones con rapidez, a fondo y de manera efectiva con el fin de tener capacidad de reacción ante las posibles denuncias. A modo

16 CONSEJO DE SEGURIDAD, El Estado de derecho y la justicia de transición en las sociedades que sufren o han sufrido conflictos, S/2011/634, párr. 12; INFORME DEL SECRETARIO GENERAL AL CONSEJO DE SEGURIDAD DE NACIONES UNIDAS, El Estado de derecho y la justicia de transición en las sociedades que sufren o han sufrido conflictos, S/2004/616, párr. 10; OFICINA DEL ALTO COMISIONADO DE LAS NACIONES UNIDAS PARA LOS DERECHOS HUMANOS, Instrumentos del Estado de Derecho para sociedades que han salido de un conflicto. Amnistías, HR/PUB/09/1, Publicación de las Naciones Unidas, Nueva York y Ginebra, 2009, pág. V.

17 CORTE INTERAMERICANA DE DERECHOS HUMANOS, caso Gelman v. Uruguay, fondo y reparaciones, $\mathrm{n}^{\circ}$ 221, 2011 párr. 198; caso Gomes Lund y Otros vs. Brasil, $\mathrm{n}^{\circ}$ 219, 2010, párr.150.

18 Sírvase de ejemplo CORTE INTERAMERICANA DE DERECHOS HUMANOS, caso La Cantuta v. Perú, fondo, reparaciones y costas, $\mathrm{n}^{\circ}$ 192, 2006, párr. 160. 
de coacción, la falta de persecución de las violaciones se interpretan como una violación de la obligación de garantizar, y en el caso de desapariciones forzosas, las obligaciones del Estado respecto a la investigación del hecho se mantiene en tanto se mantenga la incertidumbre sobre el paradero de la víctima ${ }^{19}$ (art. 7 y 9), ya que la investigación forma parte intrínseca de no dejar impunes las violaciones de derechos humanos. La Corte Inter Americana declaró en el caso de González et al. v. México la violación del derecho a la vida por parte del Estado de México ante la ausencia de investigación policial de las desapariciones de mujeres y el deficiente enjuiciamiento de los culpables, por lo que el clima de impunidad había facilitado la comisión de más crímenes ${ }^{20}$. La obligación de garantizar implica igualmente comprometer medios materiales, como dinero, bienes y servicios del Estado principalmente ante los derechos económicos, sociales y culturales. Por lo tanto la libertad del Estado para organizar y repartir sus recurso se ve limitada por las obligaciones mínimas establecidas por los derechos humanos: las obligaciones mínimas del derecho a la alimentación, al agua, a la vivienda o a la educación (ver Kälin y Künzil, 2009: 112). Además, la garantía también conlleva la reparación de las personas cuyos derechos hayan sido conculcados, lo cual va unido a la eficacia de la obligación de proporcionar un recurso efectivo. La reparación puede entrañar la restitución, la rehabilitación u otras medidas de satisfacción (apologías públicas, memoriales públicos, garantías de no repetición y cambios en las leyes y las prácticas pertinentes) especialmente desarrollados por la Corte Interamericana de Derechos Humanos (ver Ramcharan, 2011:44-51).

19 CORTE INTERAMERICANA DE DERECHOS HUMANO, asunto Gomes Lund y Otros vs. Brasil, 24 noviembre 2010, párr. 121-122; COMITÉ DE DERECHOS HUMANOS, Observación General n ${ }^{\circ} 6$ (1982), párr. 4; "los Estados deben establecer servicios y procedimientos eficaces para investigar a fondo los casos de personas desaparecidas"

20 CORTE INTERAMERICANA DE DERECHOS HUMANOS, González et al. v. México, noviembre 16, 2009, párr. 146, 151. 
Finalmente, la obligación de garantía comprende para los casos en los que el Estado no sea capaz de cumplir la obligación con sus recursos internos, la remisión de las posibles violaciones a tribunales internacionales como la Corte Penal Internacional o tribunales creados ad hoc en su caso, o también cuando las circunstancias reinantes sean más complejas mediante el establecimiento de una "Comisión de la Verdad y la Reconciliación" como las creadas para Sur África y recientemente en Brasil. La Corte Penal Internacional es muestra del interés de los Estados en garantizar la persecución y enjuiciamiento de los responsables de graves crímenes contra la comunidad internacional, aunque no en todos los casos existe obligación de los Estados de perseguirlos, se trata de los crímenes de genocidio, crímenes de guerra, crímenes de lesa humanidad, agresión y delitos contra la administración de justicia (ver Casadevante, 2011:519, 526-528, 531-534). Pero en caso de violaciones y con el fin de controlar su correcto cumplimiento, los Estados se están comprometiendo a aceptar la existencia de organismos internacionales que supervisan su comportamiento y piden cuentas de sus actos 21 .

Como se ha analizado y ejemplarizado en los párrafos precedente, el poder del Estado ha quedado limitado o redefinido convencionalmente. Es más este proceso ha sido descrito como una erosión o relativización de la soberanía estatal (ver Carrillo, 1994: 131; Liesa et al., 2001:272) y ha fundamentado la soberanía estatal como responsabilidad y protección (ver Carrillo, 1999 : 131-132; Ramcharan, 2011:242; Ssenyojo y Banderin, 2010: 398-401; LópezJacoiste, 2006: 289).

${ }^{21}$ Los comités, órganos de control creados por los pactos y convenciones para la protección y promoción de sus respectivos derechos con facultades de conciliación e investigación, son: el Comité de Derechos Humanos (1966); el Comité para la Eliminación de la Discriminación Racial (1965); el Comité contra la Tortura (1984); Comité para la Eliminación de la Discriminación contra la Mujer (1982); Comité de Derechos del Niño (1989); y el Comité de Protección de los Trabajadores Migratorios y los Miembros de su Familia (1990). 


\section{Cambios estructurales en la comunidad internacional}

Estas ideas influencian la crítica que hicieron los Estados de la práctica internacional de la segunda mitad de los años 90. Estos años estuvieron marcados por graves tragedias, entre ellos, el genocidio perpetrado en Ruanda ante la impasividad de la comunidad internacional (1994), el genocidio de los bosnios en Srebrenica (1995) y la limpieza étnica en Kosovo, a la que siguió los ataques aéreos de la OTAN (1999). Todos ellos marcados por el bloqueo de la comunidad internacional o su insuficiente implicación en la resolución de los conflictos. Sin embargo, estos hechos propiciaron un cambio de rumbo en la comunidad internacional provocando una abundante reflexión.

En primer lugar, los Estados son testigos de la amenaza que supone la rigidez de la soberanía estatal usada como un escudo para cometer serias violaciones de los derechos humanos. La soberanía como poder ilimitado, sin restricciones del respeto a la dignidad y libertades humanas, llevaba a la opresión (Hieronymi, 1996: 236239). En el marco de todas estas discusiones, el entonces Secretario General de las Naciones Unidas, Kofi ANNAN, expresa la necesidad de redefinir la soberanía y en varias declaraciones lo expresa así22. En este sentido aseveró que la Carta de las Naciones Unidas si bien protegía la soberanía nacional de los Estados (art. 2.7) esta soberanía nunca había pretendido ser absoluta. El poder de capacidad decisoria que tiene el Estado debe usarse en nombre y a favor de la población, ya que la soberanía implica responsabilidad no únicamente poder. La soberanía está siendo redefinida y concretada por la extendida conciencia de los derechos humanos individuales que son recogidos y protegidos en la Carta; y por tanto la Carta

22 Cfr. UN PRESS RELEASE, Secretary General reflects on "Intervention" in thirtyfifth anual Ditchley foundation lecture, 26 junio 1998; KOFI ANNAN, "Two concept of sovereignty", The Economist, 16 de septiembre de 1999. 
no protege el abuso que pueda hacer el Estado de sus atributos soberanos sino que los Estados son instrumentos al servicio de sus ciudadanos $^{23}$. Tras la fundamentación de la responsabilidad del propio Estado, el ex Secretario General plantea con urgencia la necesidad de que la comunidad internacional sea parte de la solución y pregunta a la Asamblea General cómo debe actuar la comunidad internacional ante crímenes como los de Ruanda y Srebrenica, y a las violaciones graves y sistemáticas de los derechos bumanos que transgreden todos los principios de nuestra humanidad común si seguimos manteniendo que la intervención es contraria al principio de soberanía ${ }^{24}$. Esta pregunta busca un cambio en las normas de Derecho internacional o en la forma de interpretarlas, que permita la acción por parte de la comunidad internacional conciliándola con el principio de no intervención en caso de graves violaciones de los derechos humanos. De esta forma lo expresa KOFI ANNAN I believe it is essential that the international community reach consensus-not only on the principle that massive and systematic violations of human rights must be checked, wherever they take place, but also on ways of deciding what action is necessary, and when, and by whom (Annan, 1999) ${ }^{25}$. Una contestación a esta petición es el informe presentado por una comisión de expertos sobre intervención y soberanía, ICISS (por sus siglas en inglés), impulsada por el gobierno canadiense, en un informe que lleva su nombre ${ }^{26}$.

${ }^{23}$ La opinión también es compartida por la Comisión Internacional Independiente de Kosovo (IICK), instituida tras la intervención de la OTAN en Kosovo, ICCK, KOSOVO REPORT, Oxford, Oxford University Press, 2000.

${ }^{24}$ UN INFORME DEL SECRETARIO GENERAL A LA ASAMBLEA DEL MILENIO "Nosotros los pueblos: la función de las Naciones Unidas en el siglo XXI", A/54/2000, párr. 217.

25 KOFI ANNAN, "Two concept of sovereignty", The Economist, 16 de septiembre de 1999.

26 COMISIÓN INTERNACIONAL SOBRE INTERVENCIÓN Y SOBERANÍA DE LOS ESTADOS (ICISS por sus siglas en inglés), La Responsabilidad de Proteger, Ottawa, 2 diciembre de 2001. 


\section{Un nuevo concepto de la "Responsabilidad de Proteger"}

La construcción de la Responsabilidad de Proteger nace con una visión holística de la protección frente a las graves violaciones de los derechos humanos. El fin de la responsabilidad de proteger es propiciar el alcance de un consenso político en torno a un nuevo concepto que reconcilie el principio de no intervención y la protección de los derechos humanos y dé respuesta a las necesidades de los individuos.

El fundamento último de esta "responsabilidad de proteger" es el cambio de una soberanía entendida como de control a una soberanía como responsabilidad del Estado y la comunidad internacional. Es decir, las autoridades estatales son responsables de proteger la seguridad y vida de su población y promover su bienestar (ver Bellamy, 2009: 35-66; Arredondo, 2012: 41-46; Espada y Hortal, 2014: 7-29). Sin embargo, en caso de graves violaciones de los derechos humanos que el Estado no pueda o no quiera atajar, o sea su responsable, es admisible la intervención de la comunidad internacional con fines de protección humana (ICISS, 2001: párr. 2.25). De tal forma que se establece una jerarquía de responsabilidades respecto a las violaciones graves de derechos humanos siendo el primer y principal responsable el Estado y subsidiariamente, cuando éste no pueda o no quiera, la comunidad internacional. Todo ello se traduce, en primer lugar, en que la responsabilidad de la comunidad internacional no es una responsabilidad general, sino que por el contrario se trata de una transferencia de competencia territorial, temporal y casuísticamente limitada (cuando el Estado no puede o no quiere). En segundo lugar, este nuevo concepto da prioridad al principio de derechos humanos sobre la soberanía y el principio de no intervención en casos extremos (ICISS, 2001: xi).

El fundamento de las responsabilidades del Estado y de la comunidad internacional tienen su respaldo en las mismas obligaciones inherentes al concepto de soberanía, el artículo 24 de la Carta de 
las Naciones Unidas, las obligaciones jurídicas que dimanan de las declaraciones, los pactos y los tratados relativos a los derechos humanos y el derecho internacional humanitario, y la práctica creciente de los Estados, de las organizaciones regionales y del propio Consejo de Seguridad. Sin embargo, el debate posterior de estas ideas y la práctica han negado la existencia actual de obligaciones jurídicas internacionales que sustenten la existencia de una responsabilidad de la comunidad internacional de actuar (ver Arredondo, 2012: 300-303; Vashakmadze, 2012: 1221), con algunas excepciones (ver Scheffer, 2008: 116-117) ${ }^{27}$, siendo calificado el deber de protección como una obligación moral (ver Welsh et al., 2005:206) o expectativas razonables (ver Welsh y Banda, 2010: 225). La mayor parte del contenido de la responsabilidad de proteger tiene un firme fundamento en el Derecho Internacional actual, la responsabilidad del Estado respecto a su población, pero parte del contenido tiene un valor legal añadido que requeriría de un desarrollo posterior para hablar de normas vinculantes, aunque es cuestionable la utilidad y viabilidad de dicho desarrollo (ver Peters, 2011: 24). No obstante, la inexistencia de una norma legal vinculante que obligue a la comunidad internacional y por tanto genere responsabilidad internacional ante su incumplimiento, no lleva a la inefectividad o vacío de la responsabilidad de proteger como estrategia.

\section{Repercusiones prácticas}

La progresiva inclusión del prisma de la responsabilidad de proteger en la actuación de la comunidad internacional ha tenido

27 No obstante, se reconoce el deber de prevenir el crimen de genocidio recogido en 2007 en el asunto sobre la Aplicación de la Convención para la Prevención y Sanción del Delito de Genocidio (Bosnia-Herzegovina v. Serbia y Montenegro). 
efectos relevantes en la protección de los derechos humanos en situaciones muy graves.

Comienzan a verse vestigios del concepto de responsabilidad de proteger en el nuevo interés de la comunidad internacional de proteger a los civiles en caso de conflictos y a las poblaciones de graves violaciones de sus derechos humanos. Así, en Kenia, tras la violencia provocada por las elecciones presidenciales en 2007, el esfuerzo diplomático de Kofi Annan en el marco de la "Responsabilidad de Proteger", consiguió un acuerdo entre las dos fuerzas políticas que puso fin a las graves revueltas. También se aprecian los esfuerzos de las Naciones Unidas para la protección de la población civil de las graves violaciones de sus derechos humanos en Côte de Ivoire en 2011 donde tras la crisis postelectoral sus Asesores Especiales recordaron el compromiso contraído por los Estados en la Cumbre de $2005^{28}$ y el Consejo de Seguridad autorizó una misión con capacidad para usar la fuerza en la protección de los civiles ${ }^{29}$. Un año más tarde se estableció en Malí una misión para apoyar al gobierno en su responsabilidad de proteger a la población ${ }^{30}$. En la República Democrática del Congo donde ante la alerta de genocidio, el Consejo de Seguridad impuso sanciones consistentes en un embargo de armas y una misión de mantenimiento de la paz con el fin de proteger a los civiles 31 , y en 2013 autorizó una "Brigada de Intervención” para proteger a los civiles ${ }^{32}$. Por último, en Sudán del Sur se autorizó una misión de mantenimiento de la paz para apoyar al gobierno en su responsabilidad de proteger ${ }^{33}$.

28 UN RESOlUCIÓN AG, Documento Final de la Cumbre Mundial de 2005, A/ RES/60/1, 16 septiembre 2005, párr. 138 y 139.

29 S/RES/1975(2011)

$30 \mathrm{~S} / \mathrm{RES} / 2085$ (2012)

31 S/RES/1896 (2009)

$32 \mathrm{~S} / \mathrm{RES} / 2098$ (2013)

33 S/RES/1996(2011), у 2131 (2013) 
En casos similares, el concepto de responsabilidad de proteger ha sido explícitamente invocado por los Representantes Especiales del Secretario General y el Asesor Especial para el Genocidio con el fin de llamar la atención al gobierno sobre su responsabilidad de proteger a la población e impulsar la acción de la comunidad internacional en los casos de Kyrgyzstan ${ }^{34}$ (2010) o Guinea ${ }^{35}$ (2010).

Para algunos, pudiera parecer que el paradigma de la responsabilidad de proteger ha sido el caso libio (2011), pero cabe preguntarse hasta que punto esta afirmación es cierta. Libia no es un ejemplo de aplicación de la doctrina de la responsabilidad de proteger hasta sus últimas consecuencias. El caso libio sorprendió por la relativa rapidez de la respuesta "decisiva" de la comunidad internacional a la crisis ${ }^{36}$. El acuerdo del Consejo de Seguridad de llevar a cabo una intervención sin consentimiento del Estado fue alumbrada por una serie de afortunadas coincidencias (claridad de los crímenes, importante apoyo regional y ausencia de intereses esenciales de los miembros permanentes del Consejo de Seguridad). Pero la forma de llevar a cabo el mandato y el resultado final de la intervención no fue satisfactorio ni acorde con las promesas de la doctrina de la responsabilidad de proteger. El impulso de la intervención fue la protección de los civiles en peligro, pero la intervención en Libia fue criticada por exceder el mandato de la Resolución 1973 (2011) del Consejo de Seguridad y propiciar un cambio de régimen. Los factores que influyeron en las

34 ASESORES ESPECIALES DEL SECRETARIO GENERAL EN LA PREVENCIÓN DE GENOCIDIO Y LA RESPONSABILIDAD DE PROTEGER sobre la situación en Kyrgyzstan, New York, 15 junio de 2010

35 ASESORES ESPECIALES DEL SECRETARIO GENERAL EN LA PREVENCIÓN DE GENOCIDIO sobre su misión en Guinea, New York, 7-22 marzo de 2010

36 S/RES/ 1970 (2011), 26 de febrero, la resolución recuerda a las autoridades su responsabilidad de roteger a la población, decreta un embargo de armas, hace una remisión de la situación a la Corte Penal Internacional. Tan solo un mes más tarde el 17 de marzo, en la resolución 1973 (2011), autoriza el uso de la fuerza con el propósito de la protección de los civiles, que se tradujo en la práctica en una "protección" mediante bombardeos aéreos 
numerosas críticas no suponen la evidencia del error o fallo de la responsabilidad de proteger sino una incorrecta aplicación, revelan una serie de errores en la consecución de la protección (también llamada "responsibility while protecting") que es necesario subsanar para perfeccionar los medios y objetivos que permitan la mejor protección de la población. Tampoco el caso sirio (2011-) ayuda a materializar esta Responsabilidad de Proteger a pesar de la continua y sistemática comisión de graves crímenes, hasta el punto de llegar a usarse armas químicas contra la población, que no alcanzó el consenso necesario para la adopción de medidas coercitivas bajo el Capítulo VII. Así, en el caso sirio lejos quedó la respuesta "oportuna y decisiva" de la comunidad internacional. La afortunada coincidencia de factores del caso libio se revela de forma contraria en el caso sirio (las críticas a la intervención libia de fondo, organizaciones regionales dubitativas en torno a la intervención, y oposición clara de China y Rusia a tomar medidas contundentes). En el caso sirio la comunidad internacional trató la crisis de forma mucho más cautelosa y menos comprometida mediante la Resolución 2118 (2013) del Consejo de Seguridad autorizando la destrucción del arsenal químico, ya que resultaba importante para acabar con uno de los aspectos del conflicto, pero que no consiguió propiciar negociaciones positivas entre las partes en conflicto por lo que el conflicto sigue adelante, y se ha agravado actualmente debido al problema añadido del terrorismo. El caso sirio es fruto de las circunstancias y está dejando a la comunidad internacional en una posición de indiferencia muy similar a la que se buscaba evitar con la responsabilidad de proteger.

Sin embargo, otras actuaciones del Consejo de Seguridad en los casos de Malí (2012) ${ }^{37}$, la República Centroafricana (2013) 38

37 S/RES/ 2085 (2012).

38 S/RES/ 2127 (2013); S/RES/ 2134 (2014). La última Resolución autoriza a la MISCA (Misión Internacional de Apoyo a la República Centroafricana), una misión de mantenimiento de la paz orquestada por la Unión Africana apoyada por tropas 
y Yemen (2014) ${ }^{39}$ continúan la tendencia marcada antes del caso de Siria, mediante el despliegue de misiones de mantenimiento de la paz con mandato de proteger a los civiles, en algunos casos con uso de la fuerza, y rectifican algunos errores cometidos en Libia.

La responsabilidad de proteger no está representada por el descontrolado caso libio. Pero tampoco queda desacreditado por la subsecuente inacción en Siria. Ambos casos están influenciados por el problema irresoluto del doble rasero en la actuación del Consejo de Seguridad. Sin embargo, el conjunto de los casos analizados demuestran que los mecanismos de prevención y alerta ante posibles graves crisis humanitarias han progresado de manera importante e impulsan a la comunidad internacional a ejercer su deber de protección de las poblaciones víctimas de graves violaciones en sus derechos humanos. En esta línea, como varios de los ejemplos analizados muestran, el Consejo de Seguridad está incorporando en su actuación la finalidad humanitaria por lo que la autorización de diversas medidas con el fin de proteger a la población civil son habituales, autorización de operaciones de mantenimiento de la paz y autorización de medidas coercitivas tras la proclamación de que las crisis humanitarias más graves pueden ser constitutivas de una amenaza a la paz (ver Mani, 2005:264-292 ; Chesterman, 2001: 112-162; Gray, 2008: 264-308; Welsh, 2008: 535-562).

francesas, a usar todas las medidas necesarias para proteger a los civiles38. Pero esta Resolución, a diferencia de la Resolución 1973, precisa con detalle los objetivos a alcanzar y la forma de llevar a cabo el mandato.

39 S/RES/ 2140 (2014). El Consejo de Seguridad ha establecido sanciones selectivas a los principales sospechosos de las violaciones de derechos humanos (prohibición de viajes y congelación de activos, prohibición a los Estados colindantes de prestar ayuda o colaborar con recursos al conflicto). Además, el Consejo de Seguridad ha creado un Comité para su supervisión y alentado a la comunidad internacional en su compromiso de prestar ayuda humanitaria y colaborar con la reforma económica y de desarrollo del país. 


\section{Conclusión}

La soberanía del Estado como poder de control ha quedado limitado, o redefinido, por medio de la adopción voluntaria de instrumentos internacionales de protección de derechos humanos que reconocen en algunos casos capacidad jurídica a organizaciones e individuos de reclamar su garantía y protección por medio de mecanismos regionales e internacionales. El Estado se ha convertido en el principal garante de los derechos humanos y el máximo responsable, como titular de la soberanía, de su respeto, protección y garantía, ya que los Estados por medio de la firma de tratados de derechos humanos ha adoptado un conjunto de obligaciones que le instituyen como el principal garante de los derechos humanos de su población. Clave en este camino ha sido el compromiso de los Estados de abstenerse de determinadas actuaciones y de tomar medidas para respetar, proteger y garantizar los derechos humanos de la persona. Todo lo analizado ha supuesto importantes cambios para el Estado que han sido descritos como una erosión o relativización de la soberanía.

Además, las tragedias acontecidas durante los años 90 pusieron de relieve la necesidad de un cambio en las normas internacionales y en su interpretación para proteger los derechos humanos cuando tenían lugar graves violaciones y los Estados no eran capaces o no querían protegerlos. Con el fin de dar una respuesta a estas tragedias e interpretando la realidad internacional actual, de forma que el Estado no es el único responsable de proteger los derechos humanos de su población, nace la "Responsabilidad de Proteger".

El concepto de responsabilidad de proteger que comienza su andadura en 2001 ha alcanzado no pocos avances en las respuestas de la comunidad internacional a las graves violaciones de derechos humanos. El concepto recoge una incipiente práctica de la comunidad internacional reflejada en el consenso en la Asamblea General 
de 2005 y $2009^{40}$. Ahora se puede afirmar que la pregunta de la comunidad internacional ante las graves crisis humanitarias ha dejado de ser una disyuntiva entre actuar o no, a ser una pregunta sobre la mejor forma de actuar en protección de los derechos humanos. El éxito de la responsabilidad de proteger reside en hacer avanzar a la comunidad internacional hacia una menor tolerancia de las graves violaciones de derechos humanos y derecho internacional humanitario, y en una mayor predisposición a prevenir sus efectos y proteger a las poblaciones de los mismos.

\section{Referencias}

Arredondo, Ricardo (2012), Intervención bumanitaria y responsabilidad de proteger: ¿hacia un nuevo paradigma de protección de los derechos humanos?, Buenos Aires: Catálogos

Bellamy, Alex (2009), Responsibility to protect: the global effort to end mass atrocities, Cambridge: Polity.

Bhuiyan, Jahid; Chowdhury, Rahman (2010), An introduction to International Human Rights Law, Leiden: Brill.

Carrillo, Juan Antonio (1996), Soberanía de los Estados y Derechos Humanos en Derecho Internacional Contemporáneo, Madrid: Tecnos.

Carrillo, Juan Antonio (1999), Dignidad frente a la barbarie, Madrid: Minima Trotta.

Cassese, Antonio (1994), Human Rights in a changing world, Cambridge: Polity Press.

Fernandez de Casadevante, Carlos (2011), Derecho Internacional de los Derechos Humanos, $4^{\mathrm{a}}$ ed., Madrid: Dilex.

Chesterman, Simmon (2001), Just War or Just Peace?, Humanitarian intervention and international law, Oxfor: Oxford University Press, 112-162.

Fernández Liesa; Llamas Cascón; y Peces-Barba (2001), Textos Básicos de Derechos Humanos, Pamplona, Aranzadi, 2001

Gierycz, Dorota (2010) "The Responsibility to Protect: A Legal and Rightsbased Perspective", Global Responsibility to Protect, 2(3), 250-266.

Gutiérrez Espada, Cesareo; y Cervell Hortal, María José (2014), Nacimiento, auge y decadencia de la responsabilidad de proteger, Granada: Comares.

40 UN RESOLUCIÓN AG, La Responsabilidad de Proteger, A/RES/63/308, 7 octubre 2009. 
Gray, Christine (2008), International Law and the use of force, $3^{\circ}$ ed., Oxford: Oxford, 254-326.

Hieronymi, Otto (1996), "Evasion of State Responsibility and the Lessons from Rwanda: The Need for a New Concept of Collective Security", J. Refugee Stud. 9 (3), 236-239.

Kälin, Walter; Künzil, Jörg (2009), The Law of International Human Rights Protection, Oxford: Oxford.

López Jacoiste, Eugenia (2006), "La responsabilidad de proteger: reflexiones sobre su fundamento y articulación", Anuario de Derecho Internacional, 22, 285-315.

Mani, Venkateshwara Subramaniam (2005), "Humanitarian" Intervention Today" Recueil de Cours de la Academia de Derecho internacional de La Haya, 313, 264-292.

Peters, Anne (2011) "The Security Council's Responsibility to Protect ?", International Organizations Law Review, 8, 1-40.

Pezzano, Luciano (2014), "Las obligaciones de los Estados en el sistema universal de protección de los Derechos Humanos", Anuario Español de Derecho Internacional, 30, 303-346.

Ramcharan, Bertrand (2011), The Fundamentals of International Human Rights Treaty Law, Leiden: Martinus Nijhoff Publishers.

Scheffer, David (2008), "Atrocity Crimes Framing the Responsibility to Protect", Western Reserve Journal of International Law, 40 (1), 111-135. 